\title{
Utilização do modelo FPEEEA (OMS) para a análise dos riscos relacionados ao uso de agrotóxicos em atividades agrícolas do estado do Rio de Janeiro
}

\author{
Using the 'Driving Force - Pressure - State - Exposure - Effects - \\ Action' (DPSEEA) model of the World Health Organization (WHO) \\ for the analysis of risks related to the use of pesticides \\ in agricultural activities in the state of Rio de Janeiro
}

Mariana de Araújo-Pinto ${ }^{1}$

Frederico Peres ${ }^{1}$

Josino Costa Moreira ${ }^{1}$
${ }^{1}$ Centro de Estudos da Saúde do Trabalhador e Ecologia Humana, Fundação Oswaldo Cruz. Rua Leopoldo Bulhões 1480/302, Manguinhos. 21041-210 Rio de Janeiro RJ.

psi_mariana@hotmail.com

\begin{abstract}
This paper seeks to apply the DPSEEA model (WHO) to identify major health risks to rural workers and the environment associated with the intensive use of pesticides in the State of Rio de Janeiro, based on an analysis of official public documents and a review of the (national and international) literature. It emphasizes the two main representative branches of agriculture in the state: family farming in the mountain region and the monoculture of sugarcane in the flatlands. Results show that the bulk of the determinants identified in the DPSEEA Matrix are related to deficiencies in actions for monitoring and surveillance of pesticide use, as well as a lack of technical assistance provided by the Public Sector in Rio de Janeiro State. Most of the actions developed in the state address the effects of pesticide exposure and, to a lesser extent, exposure to these chemicals, failing to focus on the higher levels of the matrix (such as driving forces and pressure). These are considered, by several authors, as the most appropriate when tackling the complex and systemic issues, such as the scope of this paper. By means of this study, an attempt was made to enable the application of the DPSEEA Model to assist in environmental and occupational health surveillance initiatives.
\end{abstract}

Key words Occupational health, Health indicators, Pesticides, Rural Labor, Public health
Resumo O presente trabalho utiliza como instrumento de análise o Modelo de FPEEEA (OMS) visando a caracterização dos riscos à saúde do trabalhador rural e ao ambiente decorrentes do uso intensivo de agrotóxicos no estado do Rio de Janeiro, a partir do levantamento de documentos oficiais públicos e de revisão de literatura (nacional e internacional). Enfatizam-se os dois principais ramos representativos do estado: a agricultura familiar na Região Serrana e a monocultura da cana-de-açúcar na região Norte Fluminense. Resultados mostram que grande parte dos determinantes identificados na Matriz FPEEEA encontra-se relacionada às deficiências nas ações de fiscalização e vigilância do uso de agrotóxicos e de assistência técnica por parte do Poder Público, no estado do RJ. A maioria das ações desenvolvidas, no estado, se concentra no enfrentamento dos efeitos e, em menor escala, da exposição, deixando de focar os niveis mais superiores da matriz (como as forças motrizes e a pressão), apontados por diferentes autores como mais adequados ao enfrentamento de problemas complexos e sistêmicos como o objeto do presente estudo. Buscou-se habilitar a aplicação do Modelo FPEEEA para o subsídio de ações de vigilância em saúde ambiental e em saúde do trabalhador.

Palavras-chave Saúde do trabalhador, Indicadores de saúde, Agrotóxicos, Trabalho rural, Saúde pública 


\section{Introdução}

O Estado do Rio de Janeiro apresenta um intenso e diverso setor produtivo agrícola, o qual se encontra estabelecido prioritariamente nos municípios do interior do estado ${ }^{1}$. Embora essa atividade econômica tenha uma reduzida participação no PIB estadual $\left(0,4 \%\right.$ em $\left.2008^{2}\right)$, é uma das mais tradicionais no Estado, empregando um quantitativo aproximado de 160 mil trabalhadores, o equivalente a $1 \%$ do total dos ocupados em atividades agrícolas no país ${ }^{3}$.

Diversos estudos realizados no Estado do Rio de Janeiro apresentam e discutem a modernização das técnicas agrícolas e a incorporação continuada de novas tecnologias, em pequena e em grande escala, nos diferentes processos de produção agrícola do estado ${ }^{4-11}$, incluindo os chamados agroquímicos - agrotóxicos, fertilizantes, hormônios vegetais, etc. - usados para o incremento da produtividade. Entre esses agroquímicos destacam-se, tanto pelo seu intensivo uso quanto pela sua variedade, os agrotóxicos, produtos e agentes químicos voltados ao combate de pragas que afetam as lavouras.

Apesar de não figurar entre os principais consumidores de agrotóxicos no país, em função do volume de sua produção agrícola ${ }^{2,11}$, o Estado do Rio de Janeiro apresenta um padrão de uso intensivo desses agentes químicos, com destaque para a olericultura e a floricultura de base familiar da Região Serrana ${ }^{5,7,10,11} \mathrm{e}$ a produção de cana de açúcar no Norte do estado ${ }^{4}$. Alguns estudos chegam a registrar um consumo equivalente a 56,5 quilos de agrotóxicos por trabalhador alocado na agricultura ao ano $0^{7,10}$.

A questão central que se apresenta aqui, e que se caracteriza como objeto do presente estudo, são os riscos à saúde e ao ambiente associados à intensa utilização de agrotóxicos nas diversas atividades agrícolas do Estado do Rio de Janeiro. A definição de tal e complexo objeto leva à colocação de algumas perguntas norteadoras, dentre as quais se incluem: a) que forças motrizes levam os diversos trabalhadores e empresas rurais do estado ao intensivo uso de agrotóxicos nas diferentes lavouras?; b) quais são os fatores que atuam como pressão na dinâmica de uso de agrotóxicos nos processos produtivos agrícolas do estado?; c) que alterações no ambiente são determinadas pelo uso desses agentes químicos na agricultura do estado?; d) quais os principais riscos à saúde e ao ambiente relacionados ao uso de agrotóxicos no estado do Rio de Janeiro?; e e) que ações se fazem necessárias para a garantia de condições de vida e trabalho dignas entre o gran- de contingente de agricultores do estado que manipulam continuadamente os agrotóxicos no desenvolvimento de suas atividades de trabalho?

Isto posto, o presente estudo objetiva aplicar o modelo FPEEEA, desenvolvido pela OMS no início da década de $1990^{12-14}$, na análise dos principais riscos à saúde e ao ambiente relacionados ao uso de agrotóxicos na agricultura do Estado do Rio de Janeiro. Pretende-se habilitar, aqui, esse modelo como um instrumento de análise de riscos ambientais e à saúde, capaz de organizar e categorizar as informações disponíveis em bancos de dados públicos (sobre uso de agrotóxicos e seus efeitos sobre a saúde e o ambiente), em cada um dos níveis de complexidade previstos pelo modelo, apontando, ao final, ações de prevenção e mitigação de danos, assim como indicadores de avaliação. Espera-se, ao fim, contribuir para o processo decisório e de gerenciamento de riscos associado à vigilância de populações vulneráveis face os efeitos nocivos dos agrotóxicos à saúde humana e ao ambiente.

\section{Metodologia}

\section{O Modelo FPEEEA}

Partindo do pressuposto de que existem complexas relações entre a saúde humana, o ambiente e o trabalho, a Organização Mundial de Saúde (OMS) desenvolveu, no início da década de 1990, um modelo para descrever e analisar problemas complexos originados no âmbito dessas interrelações, assim como visando propor ações de prevenção e mitigação e identificação de indicadores ${ }^{12}$. Esse modelo recebeu o nome de quadro de Força Motriz-Pressão-Estado-Exposição-Efeito-Ação (ou FPEEEA, seu acronismo em Português), uma adaptação literal do originalmente definido em Inglês (sigla DPSEEA) $)^{13-15}$. Este modelo foi desenvolvido a partir da adaptação da estrutura de Pressão-Estado-Resposta (PER), formulada pela OECD, que se baseia na análise da Pressão (P) exercida pelas atividades humanas sobre os indicadores de Estado (E) dos diferentes recursos naturais e grupos populacionais, visando a identificação de Respostas (R) específicas que garantam processos sustentáveis de desenvolvimento ${ }^{12,15}$.

O Modelo FPEEEA trabalha, prioritariamente, com a identificação e a organização de dados existentes na construção de indicadores voltados à vigilância da saúde de populações e ambientes específicos, o que permite compreender os determinantes, em diferentes níveis, do uso de determinadas tecnologias ou processos que desenca- 


\section{Caracterização da área de estudo}

O estado do Rio de Janeiro estende-se por $43.780,157 \mathrm{~km}^{2}$, compreendendo 92 municípios, o que corresponde a apenas $0,51 \%$ da área do país. No entanto, compõe uma força econômica visível no cenário nacional: seu PIB é o segundo maior do país, superado apenas pelo do Estado de São Paulo ${ }^{3}$.

Sua economia é bastante diversificada, destacando-se com maior relevância o setor de serviços e a produção industrial' ${ }^{3}$. No setor agropecuário, merecem destaque as regiões do Norte Fluminense, com o cultivo da cana de açúcar, e as regiões Serrana e Centro-Sul, com a produção de olerícolas de base familiar ${ }^{16}$. Essas duas atividades, por conta de sua participação majoritária no PIB agrícola estadual, receberam destaque na análise dos dados levantados ao longo do presente estudo.

\section{Desenho e etapas do estudo}

Trata-se de um estudo descritivo-exploratório, de base qualitativa, centrado na aplicação do Modelo FPEEEA para a análise dos riscos associados ao uso de agrotóxicos na atividade agrícola do Estado do Rio de Janeiro.

Os dados para a elaboração da matriz analítica (Figura 1) foram levantados em dois conjuntos de bases de dados: a) Bases de dados de literatura científica, incluindo as plataformas PubMed (Internacional), Lilacs (América Lati-

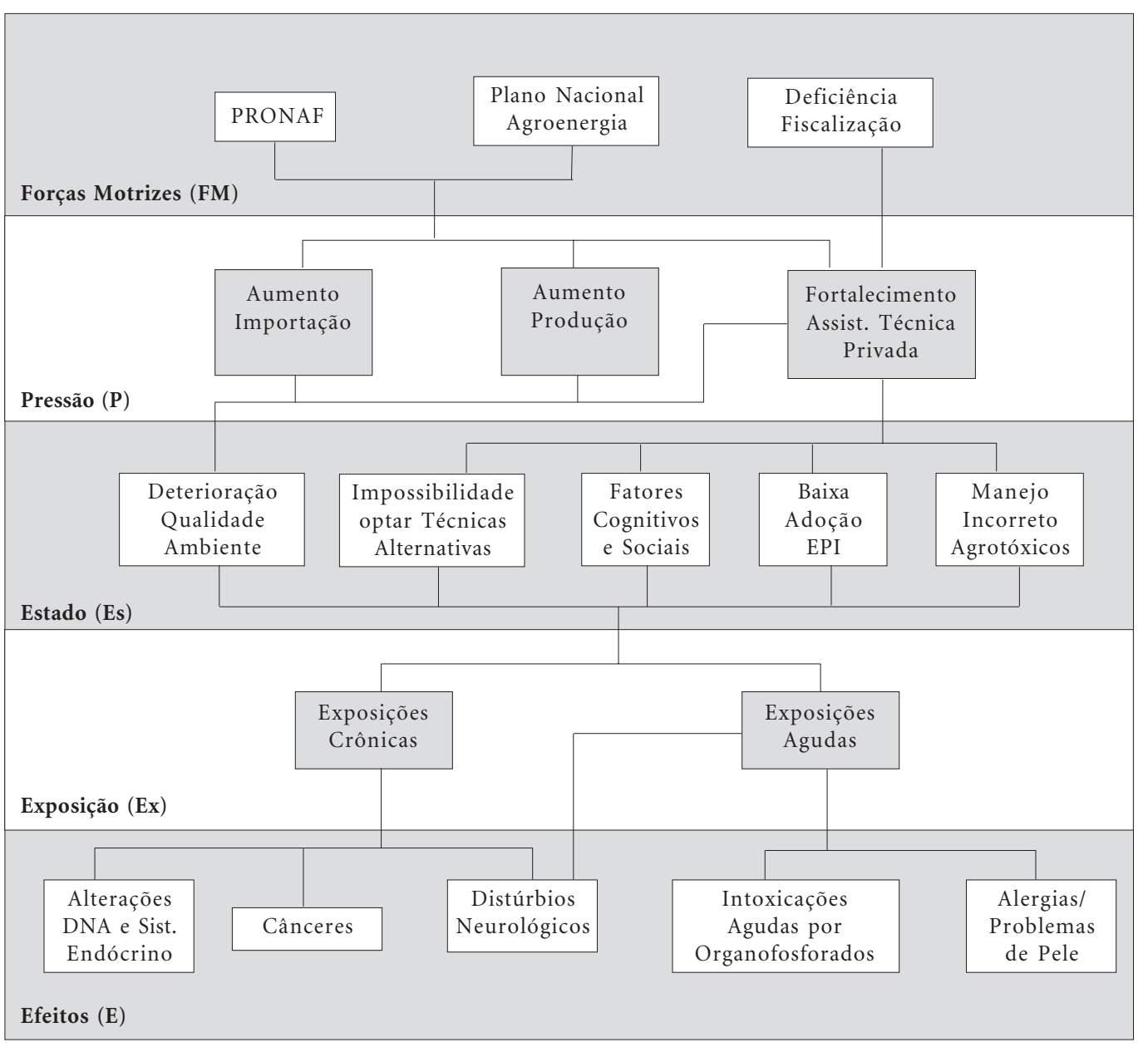

Figura 1. Representação esquemática da matriz FPEEEA relacionada ao uso de agrotóxicos na agricultura do estado do RJ. 
na) e Scielo (América Latina/Brasil); e b) Bancos de dados públicos (disponibilidade irrestrita na Internet), tais como o do Instituto Brasileiro de Geografia e Estatística (IBGE), o Sistema de Informações Tóxico-farmacológicas (Sinitox) e o Ministério da Agricultura, Pecuária e Abastecimento (Mapa), entre outros.

Os critérios de inclusão adotados foram: a) pesquisas e estudos realizados tendo como foco o estado do Rio de Janeiro e sua agricultura, trabalho rural ou agrotóxicos; b) pesquisas, estudos e dados apresentando características locais, regionais e microrregionais do trabalho rural no estado; c) pesquisas, estudos e dados sobre o regime de uso de agrotóxicos no estado; d) pesquisas, estudos e dados sobre agricultura familiar realizadas no estado; e, e) pesquisas, estudos e dados sobre grandes monoculturas cultivadas no estado. Não houve limite temporal estabelecido, registrando-se todos os estudos realizados tendo como objeto os itens acima mencionados.

Como critérios de exclusão foram estabelecidos: a) pesquisas, estudos ou dados não referentes ao estado do Rio de Janeiro; b) pesquisas, estudos e dados sobre eficiência agronômica e técnicas de produção agrícola; e, c) pesquisas, estudos e dados sobre problemas de saúde e doenças não associados à exposição a agrotóxicos.

Os dados levantados foram organizados por níveis de complexidade, tal qual recomendado pelo modelo ${ }^{12}$, a saber: a) Forças Motrizes (FM); b) Pressão (P); c) Estado/Situação (Es); d) Exposição (Ex); e e) Efeitos (E).

Para cada nível, foram identificadas Ações (A) correlatas (de atenção e vigilância em saúde), assim como indicadores (ambientais e de saúde) de vigilância em saúde ambiental. Esses indicadores foram definidos em função de cada ação identificada, segundo os critérios originalmente propostos pelo grupo técnico da $\mathrm{OMS}^{14}$.

O presente estudo se encontra em conformidade com as diretrizes da Resolução 196/96 do CNS, no que diz respeito aos preceitos éticos da pesquisa em saúde. Todos os dados apresentados e analisados foram coletados em bases de dados públicas, de acesso irrestrito (Internet, sem necessidade de senhas ou acessos com privilégio). Por essa razão, não se fez necessária a submissão do projeto ao Comitê de Ética em Pesquisa.

\section{Resultados}

A partir do levantamento e da organização do material coletado, foi possível elaborar uma matriz FPEEEA sobre o uso de agrotóxicos no estado do Rio de Janeiro e suas consequências para a saúde humana e o ambiente. A Figura 1 apresenta a representação esquemática dessa matriz, que será detalhada a seguir segundo os seus diferentes níveis.

\section{Forças Motrizes}

Dados levantados sobre a atividade agrícola do estado do Rio de Janeiro apontam dois principais elementos desempenhando papéis, na última década, de Forças Motrizes (FM) no quadro relacionado ao consumo de agrotóxicos na agricultura do estado: a) o Plano Nacional de Agroenergia; e b) o Programa Nacional de Fortalecimento da Agricultura Familiar (Pronaf).

Quanto ao primeiro, foi possível observar sua influência no estímulo à produção de cana de açúcar na região Norte Fluminense, atividade que envolve uma área de aproximadamente $137 \mathrm{mil}$ hectares, dos quais $91 \%$ estão localizados no município de Campos do Goytacazes e seu entorno $^{1,4}$. Esta atividade ocupa uma área de $4027 \mathrm{Km}^{2}$, possuindo atualmente 106 bairros e 14 distritos voltados para a produção da cana, que é destinada, prioritariamente, para a produção do álcool combustível, seguido do refino do açúcar, produção de cachaça e uso na alimentação animal ${ }^{4}$.

Dados de consumo de agrotóxicos no estado apontam para um aumento (estimado entre 100 e $150 \%$ ) no consumo de inseticidas usados no cultivo de cana de açúcar, desde o final da década de 1990, e um consumo de, aproximadamente, $85 \%$ do total de herbicidas consumidos no esta$\mathrm{do}^{4}$. O Quadro 1 apresenta os agrotóxicos mais utilizados na Região Norte Fluminense, registrados nos documentos e literatura analisados e classificados de acordo com a base de dados oficial do Ministério da Agricultura, Pecuária e Abastecimento (Agrofit ${ }^{17}$ ).

Quanto à influência do Pronaf, dados levantados apontam para um crescimento da produção agrícola de base familiar no estado (principalmente a olericultura da Região Serrana) quando comparados os resultados dos Censos Agropecuários de 1995 (ano de implantação do Pronaf) e 2006, apesar de, no mesmo período, não ter havido um aumento expressivo das áreas utilizadas para o cultivo de olerícolas ${ }^{1}$. Em um estudo nacional ${ }^{18}$ (que não incluiu o estado do Rio de Janeiro), dados semelhantes puderam ser observados, caracterizando uma associação positiva entre a concessão de crédito pelo Pronaf e o aumento do uso de agrotóxicos.

Alguns estudos ${ }^{5-7,9}$ registram a utilização de mais de 100 diferentes formulações de agrotóxi- 


\begin{tabular}{|c|c|c|c|}
\hline Tipo & Nome Comercial & Classe Toxicológica & Grupo Químico \\
\hline Inseticida & $\begin{array}{l}\text { Stron } \\
\text { Tamaron } \\
\text { Decis }\end{array}$ & $\begin{array}{l}\text { I- Extremamente Tóxico } \\
\text { I- Extremamente Tóxico } \\
\text { III- Medianamente Tóxico }\end{array}$ & $\begin{array}{l}\text { Organofosforado } \\
\text { Piretróide }\end{array}$ \\
\hline Herbicida & $\begin{array}{l}\text { Roundup } \\
\text { Imazapir }\end{array}$ & $\begin{array}{l}\text { IV- Pouco Tóxico } \\
\text { III- Medianamente Tóxico }\end{array}$ & $\begin{array}{l}\text { Glicina Substituída } \\
\text { Imidazolinona }\end{array}$ \\
\hline Fungicida & $\begin{array}{l}\text { Benlate } \\
\text { Cercobin } \\
\text { Daconil }\end{array}$ & $\begin{array}{l}\text { III- Medianamente Tóxico } \\
\text { IV- Pouco Tóxico } \\
\text { I- Extremamente Tóxico }\end{array}$ & $\begin{array}{l}\text { Benzimidazol } \\
\text { Isoftalonitrila }\end{array}$ \\
\hline
\end{tabular}

Fonte: MAPA ${ }^{17}$; Ribeiro Neto ${ }^{11}$

cos na Região Serrana do estado. Esses estudos apontam, ainda, a utilização preponderante de produtos classificados como altamente tóxicos (Classe Toxicológica II) e extremamente tóxicos (Classe Toxicológica I) na região ${ }^{5-7}$. O Quadro 2 apresenta os agrotóxicos mais utilizados nas regiões Serrana e Centro-Sul Fluminense, igualmente registrados nos documentos e literatura analisados e classificados de acordo com a base Agrofit $^{17}$.

Associado à extensa gama de agentes químicos usados intensivamente nos diferentes processos de produção agrícola do estado, os dados levantados apontam também para uma deficiência nos processos de fiscalização sobre a produção, a venda, o consumo e o pós-consumo de agrotóxicos no meio rural do estado ${ }^{4,5,7-11}$.

\section{Pressão}

As políticas incentivadoras do consumo de agrotóxicos acabaram, por sua vez, gerando diferentes elementos de Pressão (P) sobre os diferentes processos de produção agrícola do estado. Dentre esses, podemos destacar: a) o incentivo à importação de agrotóxicos; b) o aumento da produção desses insumos em território brasileiro (incluindo o estado do RJ); e, c) o fortalecimento de grupos técnicos privados de extensão rural, constituídos basicamente por agrônomos empregados pela indústria, e o comércio de insumos químicos, com amplo, fácil e direto acesso aos produtores rurais (se sobrepondo, assim, à frágil/insuficiente orientação oferecida pelos órgãos públicos).

Ao mesmo tempo em que as políticas agrícolas nacionais favoreceram o aumento da área cultivada e fortaleceram a produção e o comércio de insumos químicos (com destaque para os agrotóxicos), inclusive no estado do Rio de Ja- neiro, elas não estimularam/negligenciaram a capacitação e o treinamento de grande parte do contingente de trabalhadores envolvidos na agricultura do estado, constituindo assim outro importante elemento de pressão $0^{8-10,19-21}$.

A análise da matriz apontou que devido às deficiências observadas nos processos de capacitação $\mathrm{O}^{20,21}$ e treinamento dos trabalhadores ${ }^{8-10} \mathrm{ru}$ rais em todo o estado, a grande maioria desses agricultores conta, quase que exclusivamente, com as orientações fornecidas pelos vendedores de insumos químicos no ato da compra, o que acaba gerando problemas que serão discutidos na sequência. Em alguns estudos, esses técnicosvendedores são apontados como responsáveis por até $80 \%$ de toda a informação oferecida no campo sobre esses agentes químicos ${ }^{7,19,20}$. Segundo o Censo Agropecuário de $2006^{1}$, em todo estado, apenas $22 \%$ dos estabelecimentos receberam algum tipo de orientação técnica.

\section{Estado (Situação)}

Diversos estudos sobre o trabalho rural no estado do Rio de Janeiro ${ }^{5,7,9,20,21}$ apontam para as decorrências da combinação entre as forças motrizes (FM) e os elementos de pressão sobre o Estado/situação (Es) do ambiente (lato sensu) e do ambiente de trabalho. A análise da matriz apontou alguns dos principais elementos que compõem esse nível, incluindo: a) a deterioração da qualidade do ambiente em áreas próximas às zonas de plantio; b) a baixa adoção de equipamentos de proteção individual; c) o manejo incorreto do uso de agrotóxicos nas diferentes lavouras; d) a influência de fatores cognitivos, sociológicos e psicológicos na realização das atividades de trabalho; e, e) a impossibilidade (por motivos diversos) de optar por técnicas alternativas de manejo. 
Quadro 2. Principais agrotóxicos utilizados nas regiões Serrana e Centro Sul Fluminense

\begin{tabular}{|c|c|c|c|}
\hline Tipo & Produto & Classe OPAS/OMS & Grupo Químico \\
\hline \multirow[t]{6}{*}{ Inseticida } & $\begin{array}{l}\text { Folidol } \\
\text { Astro } \\
\text { Dipterex } \\
\text { Granutox } \\
\text { Metamidofós } \\
\text { Stron } \\
\text { Elsan } \\
\text { Kilval } \\
\text { Ortho Naled } \\
\text { Sumithion } \\
\text { Malathion }\end{array}$ & $\begin{array}{l}\text { I- Extremamente Tóxico } \\
\text { III- Medianamente Tóxico } \\
\text { II- Altamente Tóxico } \\
\text { II- Altamente Tóxico } \\
\text { I- Extremamente Tóxico } \\
\text { I- Extremamente Tóxico } \\
\text { I- Extremamente Tóxico } \\
\text { II- Altamente Tóxico } \\
\text { II- Altamente Tóxico } \\
\text { II- Altamente Tóxico } \\
\text { III- Medianamente Tóxico }\end{array}$ & Organofosforado \\
\hline & $\begin{array}{l}\text { Diafuran } \\
\text { Pirimor } \\
\text { Lannate } \\
\text { Cartap } \\
\text { Sevin } \\
\end{array}$ & $\begin{array}{l}\text { I- Extremamente Tóxico } \\
\text { II- Altamente Tóxico } \\
\text { I- Extremamente Tóxico } \\
\text { II- Altamente Tóxico } \\
\text { II- Altamente Tóxico }\end{array}$ & Carbamato \\
\hline & $\begin{array}{l}\text { Esfenvalerate } \\
\text { Decis } \\
\text { Confidor } \\
\text { Fastac } \\
\text { Ripcord } \\
\text { Ambush } \\
\text { Corsair } \\
\text { Deltametrina } \\
\text { Nor-trin } \\
\text { Bulldock } \\
\end{array}$ & $\begin{array}{l}\text { I- Extremamente Tóxico } \\
\text { III- Medianamente Tóxico } \\
\text { IV- Pouco Tóxico } \\
\text { II- Altamente Tóxico } \\
\text { II- Altamente Tóxico } \\
\text { II- Altamente Tóxico } \\
\text { II- Altamente Tóxico } \\
\text { III- Medianamente Tóxico } \\
\text { II- Altamente Tóxico } \\
\text { II- Altamente Tóxico }\end{array}$ & Piretróide \\
\hline & Vertimec & III- Medianamente Tóxico & Avermectina \\
\hline & Microzol & IV- Pouco Tóxico & Inorgânico \\
\hline & Trygard & IV- Pouco Tóxico & Triazinaminas \\
\hline \multirow[t]{4}{*}{ Herbicida } & Paraquat & II- Altamente Tóxico & Bipiridilho \\
\hline & Roundup & III- Medianamente Tóxico & Glicina Substituída \\
\hline & Tordon & I- Extremamente Tóxico & Ácido Ariloxialcanóico \\
\hline & Afalon & III- Medianamente Tóxico & Linuron (uréia) \\
\hline \multirow[t]{10}{*}{ Fungicida } & $\begin{array}{l}\text { Mancozeb } \\
\text { Dithane } \\
\text { Polyran } \\
\text { Curzate } \\
\text { Antracol } \\
\text { Midas } \\
\text { Baytroid }\end{array}$ & $\begin{array}{l}\text { I- Extremamente Tóxico } \\
\text { III- Medianamente Tóxico } \\
\text { III- Medianamente Tóxico } \\
\text { III- Medianamente Tóxico } \\
\text { II- Altamente Tóxico } \\
\text { II- Altamente tóxico } \\
\text { III- Medianamente Tóxico }\end{array}$ & Ditiocarbamato \\
\hline & $\begin{array}{l}\text { Daconil } \\
\text { Cerconil }\end{array}$ & $\begin{array}{l}\text { I- Extremamente Tóxico } \\
\text { I- Extremamente Tóxico }\end{array}$ & $\begin{array}{l}\text { Isoftalonitrila } \\
\text { Isoftalonitrila }\end{array}$ \\
\hline & Censor & III- Medianamente Tóxico & Imidazolinona \\
\hline & Fórum & III- Medianamente Tóxico & Morfolina \\
\hline & Orthocide & I- Extremamente Tóxico & Dicarboximida \\
\hline & $\begin{array}{l}\text { Titanium } \\
\text { Amistar }\end{array}$ & $\begin{array}{l}\text { IV- Pouco Tóxico } \\
\text { IV- Pouco Tóxico }\end{array}$ & Estrobulurina \\
\hline & Sportak & I- Extremamente Tóxico & Imidazolilcarboxamida \\
\hline & $\begin{array}{l}\text { Benlate } \\
\text { Cercobin }\end{array}$ & $\begin{array}{l}\text { III- Medianamente Tóxico } \\
\text { IV- Pouco Tóxico }\end{array}$ & Benzimidazol \\
\hline & Rubigan & II- Altamente tóxico & Pirimidil Carbinol \\
\hline & $\begin{array}{l}\text { Funguran } \\
\text { Cobre Sandoz } \\
\text { Cuprogarb } \\
\text { Thiovit }\end{array}$ & $\begin{array}{l}\text { IV- Pouco Tóxico } \\
\text { IV- Pouco Tóxico } \\
\text { IV- Pouco Tóxico } \\
\text { IV- Pouco Tóxico }\end{array}$ & Composto Inorgânico \\
\hline
\end{tabular}

Fonte: MAPA $^{17}$; Hossi ${ }^{6}$; Delgado e Paungarten ${ }^{5}$; Ribeiro Neto ${ }^{11}$ 


\section{Exposição}

Dados levantados para a elaboração da matriz mostram que diferentes trabalhadores rurais estão expostos (Ex) a agrotóxicos nas diversas atividades agrícolas desenvolvidas por todo o estado. Estudos que avaliaram a exposição a esses agentes químicos, através de dados clínicos e epidemiológicos ${ }^{4,20-22}$ ou de exames toxicológi$\cos ^{5-7,23-25}$ no estado, reportaram que entre $4^{5}$ e $40 \%{ }^{7}$ dos trabalhadores avaliados apresentavam sintomas ou marcadores compatíveis com intoxicação por agrotóxicos (avaliados através de anamnese clínica ou registros hospitalares e análise de indicadores biológicos, respectivamente), confirmando essa situação de exposição. Aplicando-se o menor percentual observado (4\%) ao contingente de trabalhadores rurais ocupados no estado (157.492 trabalhadores em 2006 ${ }^{1}$ ), poderíamos estimar que, anualmente, pelo menos 6.300 trabalhadores são intoxicados por agrotóxicos em todo o estado.

Essas estimativas, que podem ser consideradas conservadoras pela adoção do menor percentual de intoxicações observado nos estudos analisados, extrapolam em muito os dados oficiais que registram os casos de intoxicação por agrotóxicos notificados no estado. No Sistema de Informação de Agravos de Notificação (Sinan), foram registrados, em 2009, apenas $46 \mathrm{ca}$ sos de intoxicações exógenas por agrotóxicos agrícolas no estado e, em 2010, 54 casos, sendo 36 desses tentativas de suicídio ${ }^{26}$. Já o Sistema de Informações Tóxico-Farmacológicas (Sinitox) registrou, em 2009, 83 casos.

Para fins meramente de classificação, podemos classificar a exposição a agrotóxicos em dois principais grupos: a) exposições agudas; e b) exposições crônicas. Os efeitos decorrentes de uma exposição aguda são aqueles mais visíveis, que aparecem durante (ou logo após) o contato da pessoa com o produto, e apresentam características bem marcantes. Geralmente, esse tipo de exposição está associado a um contato com elevadas concentrações de agrotóxicos (ou agentes extremamente tóxicos) em um período relativamente curto de tempo.

Já os efeitos de uma exposição crônica podem ser visualizados semanas, meses, anos ou mesmo gerações após o período de uso/contato com estes produtos sendo, portanto, mais difíceis de visualização, muitas vezes confundidos com outros distúrbios ou, simplesmente, não relacionados ao agente causador. Isso se dá em função de uma exposição contínua a doses relativamente baixas de agrotóxicos (ou agentes pouco tóxicos) por um período de tempo mais longo, podendo ser medido em semanas ou, até, em décadas.

Em ambos os casos, a análise, na matriz (Figura 1), da relação entre Estado e Exposição mostra o peso da deficiência de orientação técnica no estado sobre os determinantes da exposição a agrotóxicos registrados nos diferentes setores da agricultura do Rio de Janeiro. Diversos estudos ${ }^{4-}$ 9,11,19-21 realizados no estado apontam uma relação direta entre a carência de assistência técnica e fatores como o manejo incorreto de agrotóxicos e a baixa adoção de equipamentos de proteção individual, fatores estes que atuam como importantes determinantes da exposição a agrotóxicos. Dados do Censo Agropecuário 2006 ${ }^{1}$ apontam que, em cerca de 296 mil estabelecimentos em todo o país, os trabalhadores não utilizam nenhum equipamento de proteção individual e, quando o fazem, a maioria adota apenas botas e chapéus.

\section{Efeitos}

Diversos efeitos à saúde (E) vêm sendo relacionados à exposição (aguda e crônica) a agrotóxicos, sobretudo a alguns dos mais utilizados no estado. A análise dos dados referentes ao estado do Rio de Janeiro mostrou que os efeitos decorrentes de exposições agudas mais registradas são aqueles causados pela exposição a inseticidas da classe dos organofosforados, bem como os carbamatos $^{27}$. Esses inseticidas atuam no organismo humano inibindo um grupo de enzimas denominadas colinesterases, que atua na degradação da acetilcolina, um neurotransmissor responsável pela condução de impulsos no sistema nervoso (central e periférico). Uma vez inibida, esta enzima não consegue degradar a acetilcolina, o que afeta toda a cadeia de transmissão de impulsos nervosos no organismo, ocasionando diversos distúrbios, que vão desde dores de cabeças a tremores, incluindo tonturas e, em alguns casos, a perda de consciência/desmaios ${ }^{28}$.

Com relação aos efeitos à saúde decorrentes de exposições crônicas a agrotóxicos, os mais observados no estado foram cânceres (identificados através de estudos epidemiológicos $\left.{ }^{29,30-32}\right)$, seguido de alterações no sistema endócrino e no DNA (avaliadas através de indicadores toxicológicos $\left.{ }^{6,33}\right)$.

\section{Discussão}

A análise dos resultados da matriz (Figura 1) possibilita o delineamento de um quadro de especial 
atenção para a Saúde Coletiva, e aponta para a importância de instrumentos como a Matriz FPEEEA para o subsídio a ações de vigilância em saúde ambiental e do trabalhador. Através da organização dos dados existentes, foi possível observar diferentes cenários e processos que acabam por determinar a exposição de um significativo contingente de trabalhadores a uma extensa gama de agentes químicos com diferentes potenciais de interferir e comprometer a saúde humana.

Como foi possível observar, em relação às Forças Motrizes (FM), duas políticas públicas nacionais têm papel significativo no quadro de uso de agrotóxicos no estado: o Plano Nacional de Agroenergia e o Programa Nacional de Fortalecimento da Agricultura Familiar (Pronaf).

O estímulo à Produção Agroenergética acabou por consolidar a cana-de-açúcar como a segunda mais importante fonte energética no país, atrás apenas do petróleo ${ }^{29}$. Tal fato encontra-se firmemente associado ao crédito oferecido, no âmbito dessa Política Nacional, à expansão e renovação dos canaviais em todo o país. No estado do Rio de Janeiro, a região Norte Fluminense é a principal beneficiária desses incentivos, o que tem causado uma série de alterações do estado do ambiente (Es), incluindo a remoção de vegetação de matas e campos, o assoreamento de rios e cursos d'água e a contaminação atmosférica, decorrente da queima dos canaviais para a colheita da cana de açúcar ${ }^{4}$.

Atualmente, a agroindústria canavieira da região passa por um processo de recuperação e relativa modernização do setor, estimulado pelos novos investimentos associados ao Plano Nacional de Agroenergia e à valorização do preço do álcool combustível/etanol ${ }^{34}$. No âmbito desse Plano Nacional, tem destaque o 'renascimento' do Programa Nacional do Ácool/Pró-Álcool, programa que tem em um de seus pilares estruturais a geração de empregos e salários no campo, contribuindo para a contenção da migração rural-urbana, além do destaque para absorção de mão-de-obra de baixa qualificação, com inserção marginal no mercado de trabalho ${ }^{34}$.

No entanto, apesar do destaque para a geração de empregos para trabalhadores com baixa qualificação, estudos apontam um grande contingente de trabalhadores expostos a um ciclo de sobrevivência miserável, que inclui a exposição a processos de trabalho penosos e exaustivos, associados à exposição a agentes químicos como os agrotóxicos ${ }^{4}$. Ademais, cabe ressaltar que os fluxos migratórios relacionados à movimentação de trabalhadores para as regiões canavieiras próxi- mos à época de colheita vêm sendo apontados como um importante problema de saúde pública, associado ao aumento de doenças transmissíveis, à violência e ao uso abusivo de álcool e drogas ${ }^{4}$.

Quanto ao Pronaf (Programa Nacional de Fortalecimento da Agricultura Familiar), alguns estudos, como o de Kageyama ${ }^{18}$, têm relacionado os incentivos à produção com o aumento da erosão e da frequência do uso de agrotóxicos. O crédito rural financiado pelo Pronaf, criado em 1995 com o objetivo de promover o apoio financeiro às atividades de agricultura e pecuária com o emprego direto da força de trabalho do agricultor e de sua família, acabou por incentivar o aumento da produtividade agrícola e o consequente incremento no consumo de insumos químicos, com destaque para os agrotóxicos. Esse Programa tem sido apontado, por diversos autores, como importante força motriz (FM) da situação de degradação ambiental ocasionada pelo consumo de agrotóxicos e outros agentes químicos ${ }^{22,35}$.

Os estudos analisados sobre a agricultura na Região Serrana/Centro-Sul do estado apontam para uma série de problemas relacionados a práticas de uso desses agentes químicos, entre os quais se destacam: a) orientação técnica deficiente, por parte do Poder Público, o que permite a ação de técnicos associados ao comércio de insumos agrícolas como responsáveis por até $80 \%$ de toda a orientação técnica disponível ${ }^{7-9}$; b) baixa adesão ao uso de equipamentos de proteção individual no manuseio dos agrotóxicos ${ }^{5,7-9,25}$; ) uso combinado de diversos princípios ativos em pulverizações ${ }^{5,7,25}$; e, d) participação de toda a família nas atividades que envolvem o manuseio de agrotóxicos, incluindo crianças e gestantes ${ }^{5,7-}$ 9,25 . Estes dados colocam os trabalhadores rurais desta região em situação de vulnerabilidade, face aos efeitos nocivos dos agrotóxicos, e justificam a importância de um olhar mais atento sobre a questão, favorecendo ações de vigilância e atenção integral à saúde desses indivíduos.

É importante destacar que o Plano Agrícola e Pecuário 2011/2012, a mais recente política nacional para o setor destinou, para essa safra, um orçamento de R\$107,5 bilhões (um aumento de $37 \%$ em relação ao orçamento de 2010/2011 e quase $50 \%$ em relação à 2009/2010) ${ }^{34}$. Tendo como dois de seus mais importantes pilares o Plano de Agroenergia e o Pronaf, é possível estimar que a situação tende a se agravar num curto prazo.

Por fim, cabe ainda o destaque à tramitação, no Congresso Nacional, de um Projeto de Lei que visa substituir a Lei 4.771 de 15/09/1965 referente ao Código Florestal brasileiro. Com signi- 
ficativas mudanças quanto à preservação de mananciais e margens de rios, ocupação de morros e encostas com lavouras e percentuais destinados a áreas de proteção, esse Projeto de Lei pode vir a se constituir como outra importante força motriz (FM) cujos impactos deverão ser sentidos, prioritariamente, na alteração do estado do ambiente (Es), com possíveis consequências para os demais níveis aqui apresentados e discutidos.

\section{Do conhecimento à prática: subsídios à vigilância em saúde ambiental e do trabalhador}

A análise da matriz possibilitou um olhar mais detalhado sobre a situação atual do uso de agrotóxicos na agricultura do estado do Rio de Janeiro. Para cada nível identificado na matriz, propõe-se, no Quadro 3, um conjunto de ações para a prevenção e a mitigação dos danos associados a esse consumo de agentes químicos no estado, destacando-se alguns dos principais indicadores possíveis para a vigilância em saúde ambiental e em saúde do trabalhador.

No campo das políticas públicas (FM), é importante destacar a necessidade de estímulo a técnicas alternativas aos agrotóxicos, assim como a garantia de assistência técnica de qualidade ao agricultor e sua família, por parte de técnicos do Poder Público, dois dos principais pontos destacados pelos autores dos artigos revisados em suas conclusões ${ }^{4,5,7,9-11,20-22,25}$. É igualmente importante a inserção de ações específicas de vigilância em saúde ambiental e saúde do trabalhador em planos e programas voltados para o incentivo da produção e da produtividade agrícolas ${ }^{10,18,20,35}$. Cabe o destaque que, nesses planos e programas, o incentivo à produção/aumento da produtividade agrícola não se configure como agente de estímulo ao aumento do consumo de agentes químicos, como observado na análise do Pronaf ${ }^{18,35}$, centrando esforços no desenvolvimento e aplicação de técnicas mais sustentáveis (menos impactantes) de produção agrícola.

Outro ponto destacado na análise dos resultados do presente estudo foi a necessidade de ampliação das ações de fiscalização nas etapas de produção, comercialização, uso e descarte de agrotóxicos de uso agrícola ${ }^{4,22,25}$. Tal fato é particularmente importante quando observamos que grande parte dos determinantes associados à exposição de agricultores aos agrotóxicos no estado encontram-se no espaço criado pela presença insuficiente do Poder Público nas ações de assis- tência técnica (abrindo caminho para um tipo de assistência técnica não-isenta de interesses comerciais) e de vigilância sobre a produção, a distribuição e o consumo de agrotóxicos ${ }^{7,20,22,35}$.

Quanto às dificuldades relacionadas à opção por técnicas alternativas aos agrotóxicos, além da carência observada quanto à assistência técnica oferecida por parte do setor Público, cabe destacar o difícil acesso a informações e a técnicas alternativas, por parte dos trabalhadores, devendo essas ser objeto de cursos específicos de capacitação, além de parte integrante dos currículos de escolas rurais em todo o estado.

Diferentes autores que discutem as aplicações do Modelo FPEEEA na vigilância ambiental em saúde ${ }^{12-15}$ apontam que as ações nos níveis de força motriz (FM) e pressão (P) mostram maior eficácia que as ações sobre efeitos gerados pelos mais diversos poluentes, uma vez que são capazes de fazer diminuir ou cessar o desencadeamento dos níveis posteriores ${ }^{14}$. Apesar disso, ainda é possível observar que a maioria absoluta das ações voltadas à vigilância de populações expostas a agrotóxicos se concentra nos efeitos (E) e, em menor grau, na exposição $(E x)^{22}$. O fato de, no estado, não haver um sistema de informação que monitore o consumo de agrotóxicos pode, também, ser identificado como uma limitação à vigilância em saúde ambiental e saúde do trabalhador. Talvez, aqui, se tenha um caminho possível para a reorientação de ações de vigilância em saúde do trabalhador e ambiental no estado, onde a contribuição do Modelo FPEEEA se mostrou interessante e promissora.

Por fim, para que todas essas ações sejam efetivadas, há que se intensificar as ações conjuntas desenvolvidas pelos diferentes ministérios (da Saúde, Agricultura e Meio Ambiente) e secretarias estaduais (idem), diminuindo a sobreposição de ações e a duplicação de gastos do orçamento estadual e, assim, contribuindo para a efetiva realização dos serviços rurais, incluindo treinamento, orientação técnica especializada, fiscalização, comercialização, destino final das embalagens, prevenção e promoção à saúde desses trabalhadores ${ }^{15}$.

\section{Conclusões}

A análise dos dados aqui apresentados e discutidos aponta para o promissor uso do Modelo FPEEEA (OMS) como um instrumento para a vigilância em saúde ambiental e saúde do trabalhador, em particular na sua relação com o uso de agrotóxicos na agricultura. Uma vez que esse 
Quadro 3. Ações e indicadores para subsídio da vigilância em saúde ambiental e saúde do trabalhador em relação ao uso de agrotóxicos na agricultura do estado do Rio de Janeiro.

\begin{tabular}{|c|c|c|c|}
\hline $\begin{array}{c}\text { Nível da Matriz } \\
\text { FPEEEA }\end{array}$ & Determinante & Ações & Indicadores \\
\hline \multirow[t]{10}{*}{ Forças Motrizes } & \multirow[t]{2}{*}{ Pronaf } & $\begin{array}{l}\text { Ênfase ao estímulo de técnicas } \\
\text { alternativas aos agrotóxicos }\end{array}$ & $\begin{array}{l}\% \text { de áreas plantadas com } \\
\text { lavouras sem agrotóxico }\end{array}$ \\
\hline & & $\begin{array}{l}\text { Reforço à assistência técnica } \\
\text { oficial ao agricultor e família }\end{array}$ & $\begin{array}{l}\mathrm{N}^{\circ} \text { de família assessoradas } \mathrm{p} / \\
\text { técnicos Poder Público }\end{array}$ \\
\hline & \multirow{3}{*}{$\begin{array}{l}\text { Plano Nacional de } \\
\text { Agroenergia }\end{array}$} & \multirow{3}{*}{$\begin{array}{l}\text { Inserção de um plano de ações } \\
\text { de vigilância em saúde do } \\
\text { trabalhador no âmbito do Plano }\end{array}$} & Frequência da assistência \\
\hline & & & $\begin{array}{l}\mathrm{N}^{\circ} \text { trabalhadores e famílias } \\
\text { cadastrados e assistidos }\end{array}$ \\
\hline & & & $\%$ cobertura das ações \\
\hline & \multirow{5}{*}{$\begin{array}{l}\text { Deficiência na } \\
\text { Fiscalização }\end{array}$} & \multirow{5}{*}{$\begin{array}{l}\text { Aumento da fiscalização sobre } \\
\text { produção, venda e consumo de } \\
\text { agrotóxicos }\end{array}$} & $\mathrm{N}^{\circ}$ notificações acidentes \\
\hline & & & $\begin{array}{l}\mathrm{N}^{\circ} \text { de empresas (indústria e } \\
\text { comércio) fiscalizadas }\end{array}$ \\
\hline & & & $\begin{array}{l}\text { Frequência da fiscalização } \\
\text { (indústria e comércio) }\end{array}$ \\
\hline & & & $\mathrm{N}^{\circ}$ sítios fiscalizados \\
\hline & & & $\begin{array}{l}\text { Frequência da fiscalização } \\
\text { (propriedades rurais) }\end{array}$ \\
\hline \multirow[t]{7}{*}{ Pressão } & \multirow{2}{*}{$\begin{array}{l}\text { Aumento na } \\
\text { Importação } \\
\text { Agrotóxicos }\end{array}$} & \multirow{2}{*}{$\begin{array}{l}\text { Implementação de plano } \\
\text { estadual para redução do } \\
\text { consumo de agrotóxicos }\end{array}$} & $\begin{array}{l}\mathrm{N}^{\circ} \text { receituários agronômicos } \\
\text { emitidos }\end{array}$ \\
\hline & & & $\mathrm{N}^{\circ}$ embalagens recolhidas \\
\hline & \multirow[t]{3}{*}{$\begin{array}{l}\text { Aumento da } \\
\text { Produção Agrícola }\end{array}$} & $\begin{array}{l}\text { Ênfase ao estímulo de técnicas } \\
\text { alternativas aos agrotóxicos }\end{array}$ & $\begin{array}{l}\% \text { de áreas plantadas com } \\
\text { lavouras sem agrotóxico }\end{array}$ \\
\hline & & $\begin{array}{l}\text { Inserção de um plano de ações } \\
\text { de vigilância em saúde do }\end{array}$ & $\begin{array}{l}\mathrm{N}^{\circ} \text { trabalhadores e famílias } \\
\text { cadastrados e assistidos }\end{array}$ \\
\hline & & trabalhador no âmbito do Plano & $\%$ cobertura das ações \\
\hline & \multirow{2}{*}{$\begin{array}{l}\text { Fortalecimento da } \\
\text { Assistência Técnica } \\
\text { Privada }\end{array}$} & \multirow[t]{2}{*}{$\begin{array}{l}\text { Reforço à assistência técnica } \\
\text { oficial ao agricultor e família }\end{array}$} & $\begin{array}{l}\mathrm{N}^{\circ} \text { de família assessoradas } \mathrm{p} / \\
\text { técnicos (Poder Público) }\end{array}$ \\
\hline & & & Frequência da assistência \\
\hline \multirow[t]{11}{*}{ Estado/Situação } & \multirow{3}{*}{$\begin{array}{l}\text { Deterioração da } \\
\text { Qualidade do } \\
\text { Ambiente }\end{array}$} & Monitoramento ambiental & Indicadores ambientais \\
\hline & & \multirow[t]{2}{*}{ Manejo ambiental } & $\begin{array}{l}\% \text { área ocupada com } \\
\text { agricultura }\end{array}$ \\
\hline & & & $\%$ áreas recuperadas \\
\hline & \multirow{2}{*}{$\begin{array}{l}\text { Impossibilidade de } \\
\text { Optar por Técnicas } \\
\text { Alternativas }\end{array}$} & \multirow[t]{2}{*}{$\begin{array}{l}\text { Reforço à assistência técnica } \\
\text { oficial ao agricultor e família }\end{array}$} & $\begin{array}{l}\mathrm{N}^{\circ} \text { de família assessoradas } \mathrm{p} / \\
\text { técnicos (Poder Público) }\end{array}$ \\
\hline & & & Frequência da assistência \\
\hline & \multirow{2}{*}{$\begin{array}{l}\text { Fatores Cognitivos } \\
\text { e Sociais }\end{array}$} & \multirow{2}{*}{$\begin{array}{l}\text { Estímulo à realização de estudos } \\
\text { de percepção de risco }\end{array}$} & $\mathrm{N}^{\circ}$ estudos realizados \\
\hline & & & $\begin{array}{l}\mathrm{N}^{\circ} \text { trabalhadores e famílias } \\
\text { participantes }\end{array}$ \\
\hline & \multirow[t]{2}{*}{$\begin{array}{l}\text { Baixa Adoção de } \\
\text { EPI }\end{array}$} & \multirow[t]{2}{*}{$\begin{array}{l}\text { Reforço à assistência técnica } \\
\text { oficial ao agricultor e família }\end{array}$} & $\begin{array}{l}\mathrm{N}^{\circ} \text { de família assessoradas } \mathrm{p} / \\
\text { técnicos (Poder Público) }\end{array}$ \\
\hline & & & Frequência da assistência \\
\hline & \multirow[t]{2}{*}{$\begin{array}{l}\text { Manejo Incorreto } \\
\text { de Agrotóxicos }\end{array}$} & \multirow[t]{2}{*}{$\begin{array}{l}\text { Reforço à assistência técnica } \\
\text { oficial ao agricultor e família }\end{array}$} & $\begin{array}{l}\mathrm{N}^{\circ} \text { de família assessoradas } \mathrm{p} / \\
\text { técnicos (Poder Público) }\end{array}$ \\
\hline & & & Frequência da assistência \\
\hline \multirow[t]{3}{*}{ Exposição } & \multirow[t]{3}{*}{$\begin{array}{l}\text { Exposições } \\
\text { Crônicas }\end{array}$} & $\begin{array}{l}\text { Inserção de um plano de ações } \\
\text { de vigilância em saúde do } \\
\text { trabalhador no âmbito do Plano }\end{array}$ & $\begin{array}{l}\mathrm{N}^{\circ} \text { trabalhadores e famílias } \\
\text { cadastrados e assistidos } \\
\% \text { cobertura das ações }\end{array}$ \\
\hline & & $\begin{array}{l}\text { Análise de marcadores } \\
\text { biológicos }\end{array}$ & $\begin{array}{l}\text { Indicadores de exposição e } \\
\text { efeito }\end{array}$ \\
\hline & & Avaliação clínica & Anamnese ocupacional \\
\hline
\end{tabular}




\begin{tabular}{|c|c|c|c|}
\hline \multicolumn{4}{|c|}{ Quadro 3. continuação } \\
\hline $\begin{array}{l}\text { Nível da Matriz } \\
\text { FPEEEA }\end{array}$ & Determinante & Ações & Indicadores \\
\hline \multirow[t]{4}{*}{ Exposição } & \multirow[t]{4}{*}{ Exposições Agudas } & \multirow{2}{*}{$\begin{array}{l}\text { Inserção de um plano de ações } \\
\text { de vigilância em saúde do } \\
\text { trabalhador no âmbito do Plano }\end{array}$} & $\begin{array}{l}\mathrm{N}^{o} \text { trabalhadores e famílias } \\
\text { cadastrados e assistidos }\end{array}$ \\
\hline & & & $\%$ cobertura das ações \\
\hline & & $\begin{array}{l}\text { Análise de marcadores } \\
\text { biológicos }\end{array}$ & $\begin{array}{l}\text { Indicadores de exposição e } \\
\text { efeito }\end{array}$ \\
\hline & & Avaliação clínica & Anamnese ocupacional \\
\hline \multirow[t]{7}{*}{ Efeitos } & $\begin{array}{l}\text { Alterações no DNA e } \\
\text { Sistema Endócrino }\end{array}$ & $\begin{array}{l}\text { Análise de marcadores } \\
\text { biológicos }\end{array}$ & $\begin{array}{l}\text { Indicadores de exposição e } \\
\text { efeito }\end{array}$ \\
\hline & \multirow[t]{2}{*}{ Cânceres } & Inquéritos epidemiológicos & Indicadores epidemiológicos \\
\hline & & Avaliação clínica & Anamnese ocupacional \\
\hline & $\begin{array}{l}\text { Distúrbios } \\
\text { Neurológicos }\end{array}$ & Avaliação clínica & Anamnese ocupacional \\
\hline & \multirow[t]{2}{*}{$\begin{array}{l}\text { Intoxicações Agudas } \\
\text { por Organofosforados }\end{array}$} & $\begin{array}{l}\text { Análise de marcadores } \\
\text { biológicos }\end{array}$ & $\begin{array}{l}\text { Indicadores de exposição e } \\
\text { efeito }\end{array}$ \\
\hline & & Avaliação clínica & Anamnese ocupacional \\
\hline & $\begin{array}{l}\text { Alergias e Problemas } \\
\text { de Pele }\end{array}$ & Avaliação clínica & Anamnese ocupacional \\
\hline
\end{tabular}

Fonte: Elaboração própria

modelo privilegia o olhar sobre dados já disponíveis - porém não organizados - e a categorização das mais diversas situações problemas em níveis distintos, com destaques para os determinantes, as ações correspondentes e os indicadores correlatos, ele (o modelo) se apresenta como um importante instrumento de subsídio à elaboração de ações de vigilância em saúde (com destaques para a vigilância ambiental e em saúde do trabalhador).

A aplicação do Modelo FPEEEA na análise dos riscos associados às diferentes atividades agrícolas do estado do Rio de Janeiro possibilitou o delineamento de um quadro complexo, onde diferentes grupos populacionais encontram-se em situação de vulnerabilidade face aos efeitos nocivos da exposição a agrotóxicos. Grande parte dos determinantes identificados na construção da matriz FPEEEA encontra-se relacionado às deficiências nas ações de fiscalização/vigilância da "cadeia" dos agrotóxicos (de sua produção/importação ao descarte final de seus resíduos e embalagens) e de assistência técnica, por parte do Poder Público, no estado.

Associado à situação, foi possível observar que a maioria das ações desenvolvidas junto a grupos populacionais expostos a agrotóxicos, no estado, se concentra no enfrentamento dos efeitos (E) e, em menor escala, da exposição (Ex), deixando de focar os níveis mais superiores da matriz (como as forças motrizes e a pressão), apontados por diferentes autores como mais adequados ao enfrentamento de problemas complexos e sistêmicos como o objeto do presente estudo.

Busca-se, por fim, estimular, a partir do exemplo apresentado e discutido ao longo do presente estudo, novas experiências relacionadas à aplicação do Modelo FPEEEA como subsídio a ações de vigilância em saúde ambiental e em saúde do trabalhador, em particular aquelas relacionadas à garantia da qualidade de vida e trabalho de indivíduos e grupos expostos a agrotóxicos em todo o país.

\section{Colaboradores}

M Araújo-Pinto, F Peres e JC Moreira participaram igualmente de todas as etapas de elaboração do artigo. 
Agradecimentos

Os autores agradecem à CAPES/MEC pelo apoio recebido, referente à bolsa de mestrado (M Araújo-Pinto) - cota institucional ENSP/Saúde Pública e pela bolsa de Estágio Pós-doutoral no Exterior (F Peres).

\section{Referências}

1. Instituto Brasileiro de Geografia e Estatística (IBGE). Censo Agropecuário 2006. Rio de Janeiro: IBGE; 2006. [acessado 2012 fev 20]. Disponível em: http://www. ibge.gov.br/home/estatistica/economia/agropecuaria/ censoagro/2006/default.shtm

2. Instituto Brasileiro de Geografia e Estatística (IBGE). Contas Regionais do Brasil 2004-2008. Rio de Janeiro: IBGE; 2006. [acessado 2012 fev 20]. Disponível em: http://www.ibge.gov.br/home/estatistica/economia/contasregionais/2008/

3. Instituto Brasileiro de Geografia e Estatística (IBGE). Pesquisa de Informações Básicas Municipais. Rio de Janeiro: IBGE; 2006. [acessado 2012 fev 20]. Disponível em: http://www.ibge.gov.br/home/estatistica/ economia/perfilmunic/default.shtm

4. Armas ED. Biogeodinâmica de herbicidas utilizados em cana-de-açúcar (Saccharum spp.) na sub-bacia do rio Corumbataí. [tese]. São Paulo: Universidade de São Paulo; 2006.

5. Delgado IF, Paumgartten FJP. Intoxicações e usos de pesticidas por agricultores do Município de Paty do Alferes, Rio de Janeiro, Brasil. Cad Saude Publica 2004; 20(1):180-186.

6. Hossi L. Genotoxicidade em floricultores da região serrana do Rio de Janeiro: Uso do teste de micronúcleo na mucosa oral. [dissertação]. Rio de Janeiro: Fundação Oswaldo Cruz; 2009.

7. Moreira JC, Jacob SC, Peres F, Lima JS, Meyer A, Oliveira-Silva JJ, Sarcinelli PN, Batista DF, Egler M, Faria MVC, Araújo AJ, Kubota AH, Soares MO, Alves SR, Moura CM, Curi R. Cien Saude Colet 2002; 7(2):299-311.

8. Peres F, Lucca SR, Ponte LMD, Rodrigues KM, Rozemberg B. Percepção das condições de trabalho em uma tradicional comunidade agrícola em Boa Esperança, Nova Friburgo, Rio de Janeiro, Brasil. Cad Saude Publica 2004; 20(4):1059-1068.

9. Peres F, Rozemberg B, Lucca SR. Percepção de Riscos no Trabalho Rural em Uma Região Agrícola do Estado do Rio de Janeiro, Brasil: agrotoxicos, saúde e ambiente. Cad Saude Publica 2005; 21(6): 1836-1844.

10. Peres F, Moreira JC. Saúde e ambiente em sua relação com o consumo de agrotóxicos em um pólo agrícola do Estado do Rio de Janeiro, Brasil. Cad Saude Publica 2007; 23(4):5612-5621.

11. Ribeiro-Neto A. Agrotóxicos, sua utilização e os indicadores de risco no estado do Rio de Janeiro. [dissertação]. Rio de Janeiro: Fiocruz; 2002.

12. Kjellstrom T, Corvalan C. Frameworks for the development of environmental health indicators. World Health Stat Q 1995; 48(2):144-154. 
13. Castro HA, Gouveia N, Escamilla-Cejudo JA. Questões Metodológicas para a Investigação dos Efeitos da Poluição do Ar na Saúde. Revista Brasileira de Epidemiologia 2003; 6(2):135-149.

14. Corvalán CF, Kjellstrõm T, Smith KR. Health, Environment and Sustainable Development. Identifying Links and Indicators to Promote Action. Epidemiology Resources Inc. 1999; 10(5):656-660.

15. Oliveira MLBC. Possibilidades de Aplicação do Modelo FPEEEA/OMS na construção de indicadores de saúde ambiental. [dissertação]. Brasília: Universidade Católica de Brasília; 2007.

16. Duarte RG. Aspectos da Geoeconomia Fluminense. Revista Eletrônica do Vestibular 2009; 2(3). [acessado 2012 fev 20]. Disponível em: http://www. revista.vestibular.uerj.br/artigo/artigo.php?seq $\operatorname{artigo}=5$.

17. Brasil. Ministério da Agricultura, Pecuária e Abastecimento (Mapa). Sistema de Agrotóxicos Fitossanitários/Agrofit. Brasília: Mapa; 2003. [acessado 2012 fev 20]. Disponível em: http://www.agricultura. gov.br/servicos-e-sistemas/sistemas/agrofit

18. Kageyama A. Produtividade e Renda na Agricultura Familiar: Efeitos do Pronaf Crédito. Agric. São Paulo 2003; 50(2):1-13.

19. Peres F. Onde mora o perigo? O processo de construção de uma metodologia de diagnóstico rápido da percepção de riscos no trabalho rural. [tese]. Campinas: Unicamp; 2003.

20. Soares WL, Freitas EAV, Coutinho JAG. Trabalho rural e saúde: intoxicações por agrotóxicos no município de Teresópolis - RJ. Revista de Econômia e Sociologia Rural 2005; 43(4):685-701.

21. Terra MAC, Pedlowski MA, Canela MC. Os agrotóxicos e a Agricultura Familiar. Marco Social 2009; 11-16. [acessado 2012 fev 20]. Disponível em: www. inct-tmcocean.com.br/pdfs/Produtos/36_Pedlowski Canela2009.pdf

22. Brito PF, Gomide M, Câmara VM. Agrotóxicos e Saúde: realidade e desafios para mudança de práticas na agricultura. Physis-Revista de Saúde Coletiva 2009; 19(1):207-225.

23. Oliveira-Silva JJ, Alves SR, Meyer A, Peres F, Sarcinelli PN, Mattos RCOC, Moreira JC. Influência de fatores socioeconômicos na contaminação por agrotóxicos, Brasil. Rev Saude Publica 2001; 35(2):130135

24. Oliveira-Silva JJ, Alves SR, Inacio AF, Meyer A, Sarcinelli PN, Mattos RC, Ferreira MF, Cunha JC, Moreira JC.Cholinesterase activities determination in frozen blood samples: an improvement to the occupational monitoring in developing countries. Hum Exp Toxicol. 2000; 19(3):173-177.
25. Castro JSM, Confalonieri U. Uso de agrotóxicos no Município de Cachoeiras de Macacu (RJ). Cien Saude Colet 2005; 10(2):473-482.

26. Brasil. Ministério da Saúde. Sinan. Dados de Intoxicação Exógena, 2007-2010. Brasília: Sistema de Informação de Agravos de Notificação; 2011. [acessado 2012 fev 10]. Disponível em: http://dtr2004. saude.gov.br/sinanweb/

27. Aardema H, Meertens JH, Ligtenberg JJ, PetersPolman OM, Tulleken JE, Zijlstra JG. Organophosphorus pesticide poisoning: cases and developments. Neth J Med. 2008; 66(4):149-153.

28. Eddleston M, Buckley NA, Eyer P, Dawson AH. Management of acute organophosphorus pesticide poisoning. Lancet 2008; 371(9612):597-607.

29. Koifman S, Koifman RJ. Stomach cancer incidence in Brazil: an ecologic study with selected risk factors. Cad Saude Publica 1997; 13(Supl.1):S85-S92.

30. Koifman S. Câncer ambiental e ocupacional na América Latina. Cad Saude Publica 1998; 14(Supl.3): S4-S5.

31. Araújo AJA, Lima JS, Moreira JC, Jacob SC, Soares MO, Monteiro MCM, Amaral AM, Kubota A, Meyer A, Cosenza CAN, Neves C, Markowitz S. Exposição múltipla a agrotóxicos e efeitos à saúde: estudo transversal em amostra de 102 trabalhadores rurais, Nova Friburgo, RJ. Cien Saude Colet 2007; 12(1):115-130.

32. Meyer A, Chrisman J, Moreira JC, Koifman S. Cancer mortality among agricultural workers from Serrana Region, state of Rio de Janeiro, Brazil. Environ Res 2003; 93(3):264-271.

33. Koifman S, Koifman RJ, Meyer A. Human reproductive system disturbances and pesticide exposure in Brazil. Cad Saude Publica 2002; 18(2):435-445.

34. Brasil. Ministério da Agricultura, Pecuária e Abastecimento. Mapa. Plano Agrícola e Pecuário 20112012. Brasília: Ministério da Agricultura, Pecuária e Abastecimento; 2011. [acessado 2012 fev 20]. Disponível em: http://www.agricultura.gov.br/arq_ editor/file/Ministerio/Plano\%20Agr\%C3\%ADcola $\% 20$ e $\% 20$ Pecu $\%$ C3\%A1rio/Plano_Agricola20112012\%20-\%20ATUALIZADO.pdf

35. Miranda AC, Moreira JC, Carvalho RL, Peres F. Neoliberalismo, Uso de Agrotóxicos e a Crise da Soberania Alimentar no Brasil. Cien Saude Colet 2007; 12(1):7-14.

Artigo apresentado em 04/04/2012

Aprovado em 10/04/2012

Versão final apresentada em 24/04/2012 